\title{
Estudo Linguístico-Etnográfico sobre a Mandioca no Baixo $\mathcal{A}_{\text {mazonas }}{ }^{1}$
}

\author{
Research Linguistic-Ethnografic Related to Cassava \\ in Amazon Lower
}

\section{Orlando da Silva AZEVEDO* Felício Wessling MARGOTTI**}

Resumo: O presente estudo aborda aspectos linguístico-etnográficos sobre a cultura da mandioca no Baixo Amazonas, localizado no Estado do Pará. O cultivo da mandioca na Amazônia constitui um campo semântico e etnográfico de grande vitalidade lexical, que se desdobra e se correlaciona com outros aspectos da vida cotidiana das populações que lá habitam. Tendo isso em conta, o objetivo desta pesquisa foi descrever o léxico utilizado pelas populações da região, correlacionado ao mundo da roça. $\mathrm{Na}$ obtenção dos dados, foram entrevistadas 10 pessoas do Igarapé do Juriti-Velho (Região do Baixo Amazonas), as quais possuíam experiência no plantio da mandioca e na produção de seus derivados. No final, conseguimos elaborar um glossário com 222 itens lexicais sobre: os nomes das mandiocas cultivadas na região; os processos de produção dos derivados; os utensílios usados no cultivo da mandioca e na produção de seus derivados. A pesquisa, em uma

\footnotetext{
* Professor da Universidade Federal do Amazonas, lotado no Polo Médio Solimões, Campus Avançado de Coari, e doutorando do Programa de Pós-Graduação em Linguística da Universidade Federal de Santa Catarina - UFSC. Contato: orlandoazevedo@ymail.com.

** Professor do Programa de Pós-Graduação em Linguística da Universidade Federal de Santa Catarina - UFSC, com doutorado em Letras (2004) pela UFRGS. Contato: wfelicio@cce.ufsc.br.

${ }^{1}$ Este trabalho, financiado pela Fundação de Amparo à Pesquisa do Estado do Amazonas - FAPEAM, foi publicado em uma versão preliminar nos Anais do evento "Simpósio Internacional Linguagens e Culturas: homenagem aos 40 anos dos programas de pós-graduação em Linguística, Literatura e Inglês da UFSC", realizado em Florianópolis, em 2011.
} 
perspectiva dialetológica, contribuiu para maior conhecimento do português amazônico.

Palavras-chave: Dialetologia. Mandioca. Dados linguísticos e etnográficos.

Abstract: This research approaches linguistic-ethnographic aspects related to cassava cultivated in Amazon Lower Region in Pará. The cultivation of cassava in Amazonia is a semantic and ethnographic field of vitality, which unfolds and correlates with other aspects of daily life of the people who live there. Therefore, the aim of this study is to describe the lexicon used by local population by correlating with the around environmental. In the obtaining of the data, we interviewed 10 people from Igarapé of Juriti-Velho (Amazon Lower Region), which have had experience in planting cassava production and its derivatives. In the end, we organize a glossary with 222 lexicons in relation to: the names of cassava cultivated in the region; in the processes related to cassava cultivation and production of its derivatives; on the utensils used in the manufacture of cassava products. The research, from the perspective dialectology, contributed to greater knowledge of Portuguese Amazon.

Key-words: Dialectology. Cassava. Linguistic and ethnographic data.

\section{Considerações Iniciais}

A cultura da mandioca é praticada como meio de subsistência pelos índios de toda a Amazônia desde tempos imemoriais, de modo que se tornou um legado para a população cabocla formada após a colonização portuguesa.

São inúmeras as contribuições que a raiz da mandioca pode oferecer à alimentação de populações autóctones e alóctones na Região Amazônica. Dentre as diferentes formas que a mandioca se apresenta no cardápio do dia a dia, encontramos a farinha, que é um complemento alimentar apreciado durante o almoço e a janta, combinada com carnes de peixes, como tambaqui, jaraqui, pacu etc..

Os caboclos mais velhos da região dizem que a força de um homem está na farinha que come, pois é ela que fornece energia para desempenhar seus trabalhos rotineiros. Do ponto de vista linguístico, a cultura e o consumo dos subprodutos da mandioca na Amazônia constituem um domínio 
semântico e etnográfico de grande vitalidade lexical, que se desdobra e se correlaciona com outros aspectos da vida cotidiana das populações que lá habitam.

Com vistas a descrever aspectos lexicográficos do homem amazônico relacionados à cultura da mandioca, realizamos algumas entrevistas com moradores do Igarapé do Juruti-Velho, localidade situada no Baixo Amazonas, interior do Estado do Pará.

Escolhemos essa localidade para a realização da pesquisa por ser uma das áreas mais tradicionais no cultivo da mandioca no Baixo Amazonas e por ter sido um centro de exportação de farinha (o subproduto da mandioca mais valorizado comercialmente nessa região) para Parintins, Manaus e outros lugares do Estado do Amazonas e do Estado do Pará.

\section{Contornos da Pesquisa}

A coleta de dados foi realizada na última semana do mês de agosto de 2010 no Igarapé do Juruti-Velho, e nos baseamos na aplicação das seguintes perguntas: 1. Quais as mandiocas conhecidas na região?; 2. O que se pode fazer com a massa da mandioca?; 3. Como é feito o roçado? O que se usa para fazer farinha, beiju, tapioca, tucupi etc.? Como se faz o tarubá? Como se faz o pajiroba? O que é puxirum? Qual é a melhor data para fazer a roça? O que é Centro? Existe diferença entre mandioca e macaxeira? De que é feito o barracão?

$\mathrm{Na}$ coleta de dados, além da observação in loco e da fotografia, foi usado um microfone acoplado a um gravador de voz digital durante as entrevistas com moradores locais, os quais trabalham ou trabalharam por muitos anos no cultivo da mandioca.

A composição do corpus foi feita a partir das entrevistas realizadas com 10 pessoas experientes, por isso não tivemos o propósito de estabelecer parâmetros diatópicos, diastrático, diageracional, diassexual, etc., uma vez que o que nos interessou foi somente saber as lexias referentes ao domínio semântico da roça. No Igarapé do Juruti-Velho, por exemplo, o nome de uma determinada espécie de mandioca é o mesmo para homens e mulheres em diferentes faixas etárias, ou seja, não ocorre variação lexical considerando os parâmetros sociais.

Partimos do pressuposto de que qualquer que seja a cultura desenvolvida em um lugar, o homem certamente vai se utilizar de um 
repertório linguístico para se correlacionar com o mundo que o cerca. E assim sucede com a linguagem utilizada pelos pescadores, pelos criadores de gado, pelos caçadores, pelos madeireiros e nas diferentes estratificações sociais.

No desenvolvimento do trabalho foram usadas as iniciais dos nomes das pessoas que participaram diretamente das entrevistas, com vistas a preservar a privacidade das informações e a identidade dos entrevistados. Além disso, para facilitar a compreensão dos termos utilizados na descrição do léxico, adotamos no glossário as abreviaturas adj. para adjetivo, adv. para advérbio, v.t.d. para verbo transitivo direto, v.t.i. para verbo transitivo indireto, v.i. para verbo intransitivo, s.m. para substantivo masculino e s.f. para substantivo feminino. Foram também usadas aspas em palavras, expressões e citações que caracterizam a linguagem dos moradores do Igarapé do Juruti-Velho. A partir das informações coletadas, compusemos o léxico relacionado ao cultivo da mandioca e a de seus derivados.

\section{A Cultura da Mandioca na Amazônia}

Em um estudo etnográfico sobre a exploração de produtos naturais na Amazônia. Pezzuti e Chaves (2009) descrevem os índios Deni, habitantes da área de interflúvio entre os rios Juruá e Purus, no Estado do Amazonas, e a relação deles com a natureza e com populações não indígenas. Nesse artigo, mencionam a agricultura dos vegetais que são produzidos na roça, entre a mandioca, que é um dos alimentos apreciados por essa comunidade indígena. De outra parte, Chisté et al. (2010) afirmam que o processamento artesanal da mandioca e de seus derivados nas comunidades rurais do Estado do Pará serve para diminuir a quantidade de cianeto (HCN, um ácido prejudicial à saúde), tornando os subprodutos consumíveis sem o risco de envenenamento. Em outro trabalho, Gonzaga et al. (2008) mencionam a manipueira, um subproduto da farinha de mandioca (Manihot Esculenta), que tem propriedade inseticida, como uma possível alternativa no combate e controle de pragas da região. Souza et al. (2008) afirmam que algumas características físico-químicas de mandiocas oriundas do Vale do Juruá, no Estado do Acre, dependem da variedade utilizada no processamento, e citam alguns tipos como: paxiubão, im221, caboquinha, panati, araçá, colonial, branquinha, mansa e brava, dentre as quais se destacaram as variedades araçá, colonial e branquinha como as mais apropriadas para a produção de farinha, por apresentarem alto teor de proteínas e carboidratos na composição. 
Fausto (2006) descreveu que, no Alto Xingu, as mulheres indígenas lavam a mandioca para retirar a tapioca, com a qual fazem beijus; além disso, aproveitam a água residual da lavagem para fazer uma espécie de mingau doce. $\mathrm{O}$ pesquisador cita também os paracanãs, povo tupi-guarani no Estado do Pará, os quais deixam a mandioca na água durante quatro dias para amolecer e tufar. Na sequência, amassam a mandioca, fazendo bolotas para secarem ao sol e para diminuir a quantidade de ácido cianídrico $(\mathrm{HCN})$. Após terem certeza de que o líquido da massa escorreu no moquém (varas postas horizontalmente), iniciam os demais processos como peneiração e torragem para obterem uma farinha grossa e amarela, que esses índios chamam de farinha puba. O termo puba, na linguagem dos paracanãs, significa podre, mole ou fermentada. Segundo Fausto (2006), existem ainda centenas de variedades de mandiocas que pertencem ao gênero Manihot, e exemplifica o conhecimento que determinado povo indígena tem desta forma: os paracanãs reconhecem apenas oito, sendo uma delas doce; os kuikuros do Alto Xingu reconhecem em torno de cinquenta e, na Amazônia central e oriental, as populações indígenas preferem cultivar mandiocas bravas ou amargas, enquanto na parte ocidental plantam cultivares doces.

Entre os trabalhos de cunho etnográfico, citamos o de Mattos (2001), no qual há a definição de etnografia como pertencente ao ramo da antropologia, cuja finalidade é estudar e descrever aspectos culturais de um grupo, comunidade ou povo; e ele mostra que a abordagem etnográfica não deve seguir padrões rígidos ou pré-determinados, pois depende muito do senso do pesquisador sobre o objeto de estudo. Em outra pesquisa de cunho etnográfico, Rodrigues Júnior (2007), ao analisar trinta e sete resumos de dissertações disponíveis no Banco de Teses on-line da CAPES, encontrou resultados que sugerem que a etnografia é mais empregada como instrumento de análise do que como uma lógica de investigação, em se tratando de pesquisas relacionadas ao ensino e aprendizagem de línguas estrangeiras.

Segundo a EMBRAPA ([s.d.]), o nome científico da mandioca é Manihot Esculenta Cranť, da família da Euphorbiaceae, que é originária do maior produtor sul americano: o Brasil. Porém, ela é cultivada em outros países da América do Sul e em outros continentes, como o africano, cujo maior produtor é a Nigéria; e o asiático, sendo a Índia a maior produtora. Existem inúmeras variedades em solo brasileiro. Por exemplo, Mendes et al. (2006) catalogaram 2.871 espécies nas regiões Norte e Nordeste. O imenso sucesso dela é devido à fácil adaptação a quase todos os tipos de solos, tais como: 
arenoso, argiloso e o que contém húmus. Além do mais, ela não exige conhecimento técnico avançado sobre o plantio e manuseio e é rica em carboidratos, presentes in natura, no beiju produzido artesanalmente e até nos subprodutos industrializados, como fécula.

Trabalhos de cunho lexical-etnográfico são ainda incipientes na região Amazônica. Apesar disso, mencionaremos dois trabalhos realizados em épocas diferentes no Estado do Amazonas. As duas pesquisas utilizaram, na elaboração do questionário semântico-lexical, itens lexicais relacionados à cultura da mandioca. O primeiro estudo é o Atlas Linguístico do Amazonas - ALAM, da autoria de Cruz (2004), que foi desenvolvido em forma de tese em seis pontos de inquérito (Barcelos, Tefé, Lábrea, Humaitá, Itacoatiara e Parintins). Mais tarde, a autora estendeu a pesquisa para as cidades de Benjamin Constant, Eirunepé e Manacapuru. No questionário semânticolexical do ALAM foram encontradas as seguintes lexias: pé-de-moleque, pirão, maniva, anauaçu, beiju-cica, beiju de mandioca lavada, bonitinha, caçuá, casa de farinha, chibé, crueira, enfornar, espalhadora, farinha d'água, fornada, forno, gamela, goma, macaxeira, manicujá, peneira, prensa, tapioca, tipiti e tapiriti (massa seca no tipiti). Da mesma forma, na outra pesquisa, realizada por Corrêa (1980) nas cidades de Itacoatiara e Silves, há a utilização no questionário semântico-lexical de muitos lexemas também referentes ao domínio semântico da mandioca, como: casa de farinha, casa de forno, cozinha de forno, garera, gamela, tipiti, prensa, masseira, forno, paneiro, peneira, uaturá, jamachi, caçú, remo, cuiapéua, taru, rodo, farinha toco mole etc.

No tópico seguinte descrevemos o léxico da roça no Igarapé do Juruti-Velho.

\section{Descrição dos Dados}

\subsection{A mandioca no Igarapé do Juruti-Velho}

Existem variedades de mandioca que se desenvolvem mais rapidamente, mas são frágeis às ações do tempo, e outras que demoram mais de um ano para apodrecer no solo. O caboclo, em se tratando do Igarapé do Juruti-Velho, região em que foi realizada a coleta de dados para a presente pesquisa, pode escolher para plantar entre muitas variedades, porque a natureza fez uma seleção genética específica como, por exemplo, a que produz mais tapioca ou a que possui muito líquido para o tucupi. 
No discurso enunciativo do homem roceiro são comuns os nomes como árvore, avri para se referir à maniva ou à maniveira. A maniva é um dos termos bastante usado pelos moradores do Igarapé, os quais não conseguem distinguir diferenças semânticas entre maniva e maniveira. Da mesma forma, são também comuns os termos em referência à cor mais predominante nas polpas da mandioca como amarela, amarelada, amarelinha $\mathrm{e}$ amarelaça.

As mais cultivadas na região são "Coraci" e "Pororoca" com a casca "amarelada" e bem branca por dentro, pois "dá" muitas raízes e seu tempo de colheita é prolongado, porque demora um ano para "amadurecer" e pode ficar até um ano a mais no solo sem apodrecer (EAQ. 41 anos, antigo $2^{\circ}$. Grau completo). A mandioca "Pororoca" é a mais "forte" (em termos de concentração de veneno) do que todas as outras mandiocas e "demora de um a dois anos pra dar raízes e um ano a mais pra amadurecer. Ela demora de um ano a dois anos no solo sem apodrecer. Ela custa muito dá. Elas são "raízes grande" (LSA, 42 anos, alfabetizado e AGG, 28, oitava série).

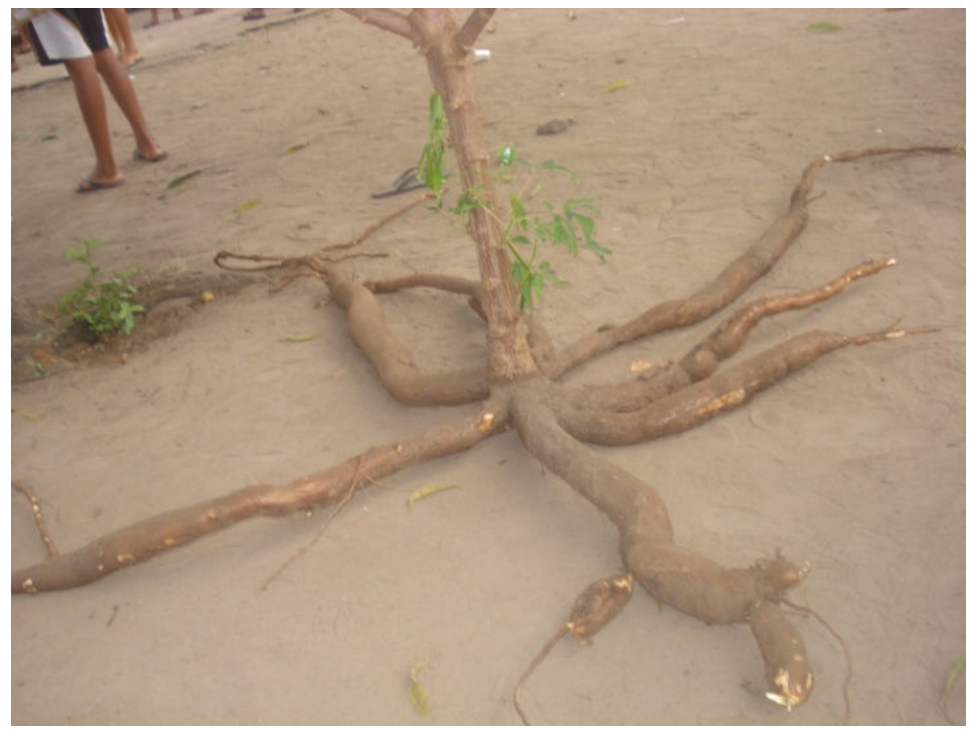

Fonte: Pesquisa de campo, 2010.

Figura 1 - Raízes da mandioca coraci 


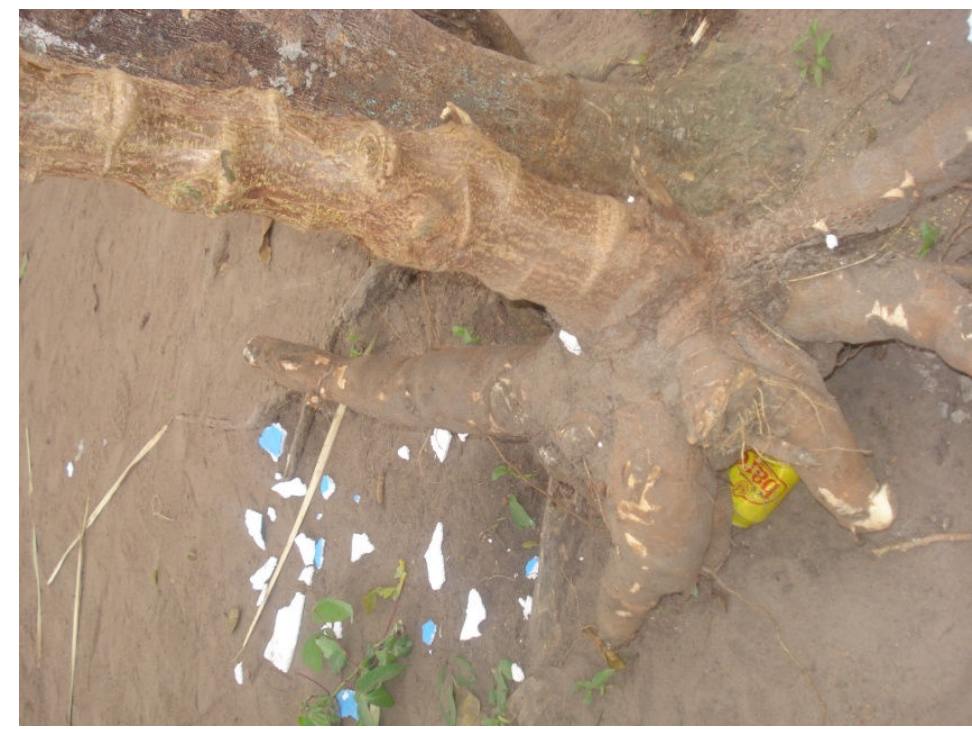

Fonte: Pesquisa de campo, 2010.

Figura 2 - Raízes da mandioca pororoca

Os moradores fazem a nomeação das variedades de mandioca, correlacionando-as a nomes de objetos, frutas, peixes e de outros animais conhecidos da região. Entre as variedades usadas e faladas pelo Igarapé foram encontradas as seguintes no repertório linguístico local: "tucumã", "miriti”, "coraci”, "pororoca”, “achadinha”, "marrequinha”, "coraci branca”, "traíra”, "branca", "paixão”, “ajuda”, "coraci preta”, "coraci amarela”, "pororoquinha”, “mamuru”, “zolhuda”, “olímpia”, “camarãozinho”, "bodó" ou "acari", "aruanã", "macaxeira", "macaxeira manteiga", "macaxeira vermelha", "macaxeira jabuti", "macaxeira amarela", "manicuera", "manicuera branca”, "manicuera roxa", "menina”, "pagoa”, “carga de burro”, “arpão”, "socó”, “juritizinho”, "iá”, “tambaqui”, “estaquinha”, "estaca grande”, "perereca”, "rosarinho”, "tapaiúna”, “anuecê”, "inajaj", "jerimum" e "leandra".

Todas essas denominações de variedades de mandioca não foram encontradas como referentes de mandiocas nos grandes dicionários, com exceção dos seguintes termos: 
- manicuera: os dicionários Aurélio (2009) e Houaiss (2009) definem como uma espécie de mandioca, cuja etimologia do nome remonta ao tupi com a seguinte transcrição fonética [mani 'kuera];

- tucumã: sua lexia remonta ao tupi e é transcrita como tukú mã, que é uma espécie de fruta oval comestível em toda a região amazônica e foi definida somente pelo Aurélio (2009) como sendo uma espécie de mandioca com o tronco vermelho;

- macaxeira: é definida nos dois dicionários como sendo uma espécie de mandioca.

A maioria das lexias encontradas no falar do roceiro do Igarapé do Juruti-Velho é de origem indígena, por isso constituem-se em empréstimos feitos do tupi, que, por extensão semântica, passaram a denominar os tipos de mandioca mais cultivados na região. As extensões semânticas, que não sofreram processo derivacional nem composicional, aconteceram com as palavras pertencentes a vários domínios semânticos mostrados na tabela abaixo:

\begin{tabular}{|c|c|c|c|c|c|c|c|}
\hline $\begin{array}{c}\text { Peixes } \\
\text { regionais }\end{array}$ & $\begin{array}{c}\text { Frutas } \\
\text { regionais }\end{array}$ & Ave & Anfíbio & $\begin{array}{c}\text { Nomes } \\
\text { próprios }\end{array}$ & Instrumento & $\begin{array}{c}\text { Fenômeno } \\
\text { natural }\end{array}$ & $\begin{array}{c}\text { Classes } \\
\text { diversas }\end{array}$ \\
\hline Aruanã & Tucumã & Socó & Perereca & Leandra & Arpão & Pororoca & Ajuda \\
\hline Bodó & Miriti & & & Olímpia & & & Paixão \\
\hline Acari & Jerimum & & & Coraci & & & Branca \\
\hline Tambaqui & Inajá & & & & & & Menina \\
\hline Traíra & & & & & & & Iá \\
\hline
\end{tabular}

Fonte: Pesquisa de campo, 2010.

Quadro 1 - Extensão semântica para os nomes das mandiocas no Igarapé do Juruti-Velho

Colocamos os termos ajuda, paixão, branca, menina e iá como pertencentes a classes diversas devido à dificuldade em reuni-las a um único campo semântico, mesmo sendo tais palavras substantivas. $\mathrm{O}$ vocábulo ajuda sofreu processo de derivação regressiva do verbo ajudar, tornando-se um substantivo feminino com o sentido de "auxílio" e "socorro" na definição dada pelo Houaiss (2009). O termo paixão, antes de passar a denominar uma variedade de mandioca, possuía outras definições como "sentimento", "emoção", "martírio de Cristo" e de "anel metálico fixado na sobrequilha 
para segurar a braga da amarra" (HOUAISS, 2009, p. 1423). O termo branca, por sua vez, pertencia à classe dos adjetivos, mas, por conversão, tornou-se um substantivo. A forma menina manteve a mesma classe gramatical na transposição semântica de nome de pessoa para nome de mandioca. O termo iá (HOUAISS, 2009, p. 1039), antes de adquirir um novo referente, apresentou três definições: interjeição, exprimindo asco; substantivo feminino, com a ideia de dança; e substantivo feminino, no sentido de mãe. Nesses nomes das mandiocas, o falante do Igarapé usou a mesma lexia, que já possuía um ou mais significados primitivos. A forma mamuru, apesar de não ser encontrada em obras lexicográficas, sobrevive há décadas no repertório linguístico da região do Baixo Amazonas, pois se refere tanto ao nome de uma variedade de mandioca como a um lugar interiorano nas proximidades da cidade de Parintins, no Estado do Amazonas.

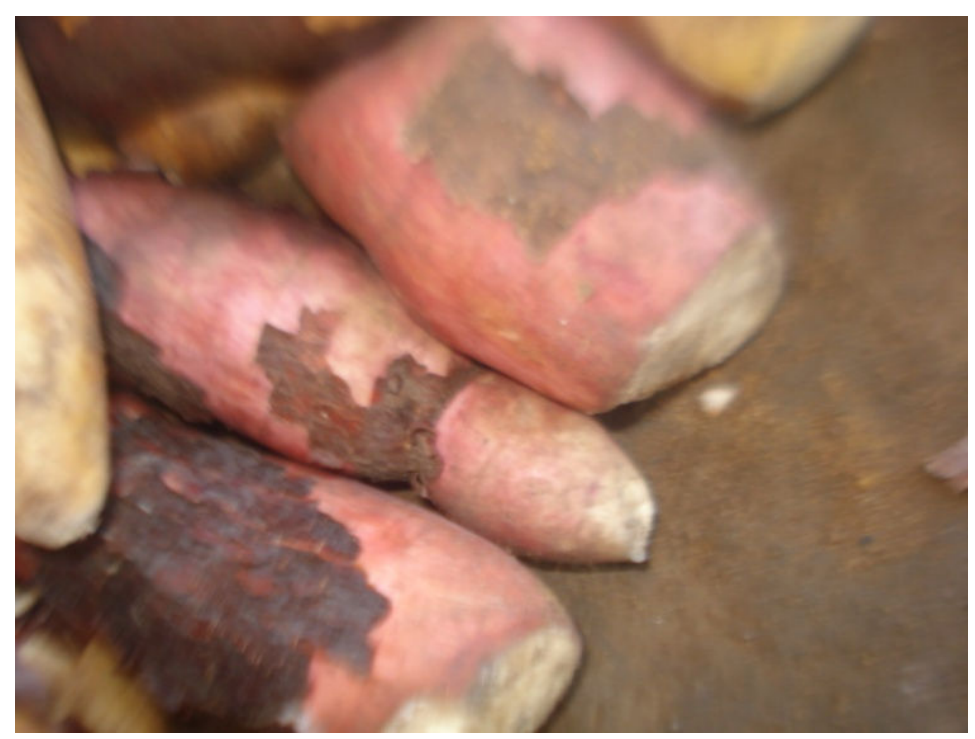

Fonte: Pesquisa de campo, 2010.

Figura 3 - Mandioca achadinha 


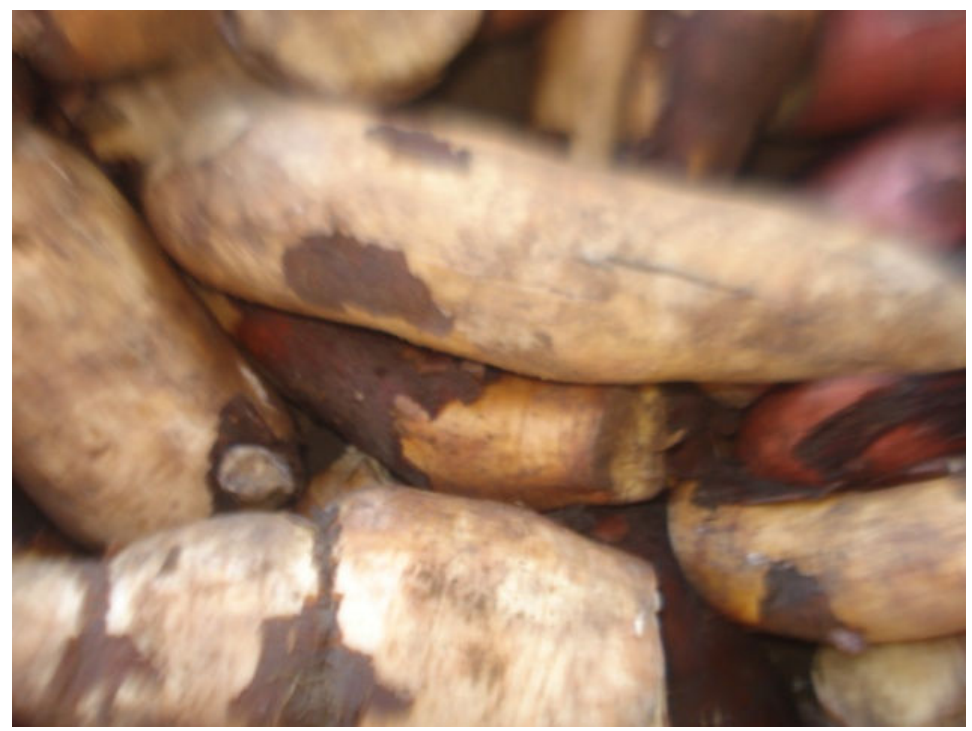

Fonte: Pesquisa de campo, 2010.

Figura 4 - Mandioca olímpia

$\mathrm{Na}$ linguagem do caboclo do Igarapé do Juruti-Velho, mandioca é sempre a mais venenosa, enquanto a macaxeira, embora seja uma espécie de mandioca, não é venenosa, ou seja, não contém demasiadamente ácido cianídrico (HCN). Portanto, mandioca e macaxeira têm suas definições diferenciadas e cristalizadas na linguagem coloquial do caboclo do Igarapé.

Existem outras variedades de mandioca cujas designações os informantes não conseguiram lembrar, pois costumam trabalhar com número limitado nas roças, de modo que outros tipos de mandioca vão se perdendo com o tempo, porque deixam de ser cultivadas. O curioso é que os cultivadores de mandioca conseguem mensurar quais mandiocas contêm muito ou pouco veneno e quais são as mais apropriadas para fazer os derivados, além da farinha.

\subsection{O barracão da farinha}

Ele é feito com "varas" grossas da árvore "cariúba", as quais são os "esteios" das bases principais, e de "varas" finas, que são os "caibros" de 
árvores como "Pau Caboclo", "Envira"2, "Moorta", que recebem a cobertura de "palha". Na "cumeeira", é colocado um "jacaré", que é feito de "palha preta", para evitar que chova no "meio do barracão". Este pode ter dimensões pequenas, médias ou grandes, dependendo da quantidade de famílias que trabalham nele e da necessidade de ampliação para maximizar a produção de farinha. O lugar onde se produz farinha e outros derivados pode ser construído permanente ou provisoriamente, próximo à casa dos roceiros ou muito mais distantes, nos chamados centros.

\subsection{A divisão do trabalho}

A divisão do trabalho no cultivo da mandioca e na produção de farinha não obedece verdadeiramente a uma hierarquia rígida, mas os papéis desempenhados pelos homens e pelas mulheres possuem certas peculiaridades, pois eles são os responsáveis pelo sustento da casa, e devem pescar nos lagos chamados de Araçá Grande e Araçazinho, principalmente, com malhadeiras ou com caniços nos igapós. Eles caçam durante a noite em um determinado lugar chamado de "Moitá", onde passam veado, tatu, paca, cotia, "catitu" ou "quexada" (os nomes que eles chamam para o porco do mato) ou, então, aves como o jacu. Entretanto, a atividade principal que o homem faz é a plantação de mandioca, feita próxima à casa, que fica na "bera" do Igarapé ou, então, que é feita distante, nos grandes "centros"3. Além disso, os homens são responsáveis pela construção da casa, que antigamente era feita de "palha" e atualmente é feita de madeira. Embora os homens façam todas essas atividades, eles participam de outras com menor frequência, tais como lavar roupas, cuidar do peixe e fazer o almoço e a janta. Por outro lado, as mulheres cuidam dos afazeres domésticos e dos filhos, mas também "têm" uma participação muita ativa no plantio e na produção da farinha e, principalmente, na fabricação de seus subprodutos.

${ }^{2}$ Envira é o nome da casca de um pau ou planta também chamada de envira. Devido à resistência da fibra, é usada como alça nos paneiros, por onde o roceiro coloca a cabeça. Para designar a mesma fibra, usa-se também o termo "embira”, que é extraída do "pau de embira".

${ }^{3}$ Centros é o local dentro da mata onde fica o barracão de farinha. 


\subsection{O plantio da "maniva"}

Para fazer o plantio da "maniva", o caboclo roceiro precisa cavar com a enxada, abrir as "valas" para "interrar" as manivas "decotadas" ou cortadas. Essa "vala" ou buraco recebe o nome de "manicujá". Quando possível, os trabalhadores são divididos em três grupos: um que vai abrindo as "valas" com a enxada; outro composto pelos espalhadores ou "espalhaderas", que jogam os pedaços de "maniva" na "vala" ou "manicujá"; e, por último, o terceiro grupo, que vai “interrando" em pé.

Segundo o ex-agricultor EAQ, o caboclo trabalha o solo através do fogo, e vai usar o verão amazônico para fazer a queimada. Ele começa a fazer o roçado em torno junho e julho, e a queimada ocorre em setembro ou em outubro, no forte do verão. A plantação começa em novembro, mas existe alguma variação, em que se planta até mesmo em janeiro. Portanto, existem épocas diferentes para a "derribada" das árvores, para a secagem do roçado e para o plantio das "manivas". Depois de alguns meses ou um ano, dependo da variedade plantada, o roceiro começa a fazer a colheita.

Para facilitar o plantio, o responsável ou interessado promove o “ajuri”, que pode ser composto por 10, 15, 20, 30 ou mais pessoas, que irão ajudar no trabalho. "Ajuri” é uma troca tradicional de diárias, que caracteriza muito bem a cultura da mandioca, uma vez que é quase inviável empregar alguém na roça. As pessoas costumam, no interior, dizer desta forma: "eu ainda vô naquele ajuri da pessoa. O ajuri significa ajudá, pode ser puxirum", significa muitas pessoa" (DSA). Embora a senhora de 70 anos mencione o termo "ajuri", a palavra mais comum usada no Igarapé do Juruti-Velho é "puxirum".

\subsection{A produção da farinha e seus instrumentos de manufatura}

O informante EAQ disse que a forma como se produz a farinha no Juruti-Velho é rústica, porque o caboclo não tem organização ou seria uma

${ }^{4}$ Para o mesmo fim e significado, no Atlas Linguístico-Etnográfico da Região Sul do Brasil (ALTENHOFEN; KLASSMANN, 2011, p. 312), foram registradas as seguintes variantes lexicais: mutirão, puxirão (pixurum, pixirum), reunião, ajuda, ajutório. 
atividade vista recentemente como "um quebra galho", em função da entrada da mineração de bauxita, cuja exploração está a cargo da empresa americana Alcoa, que desviou os olhares dos ribeirinhos para outro tipo de trabalho. No entanto, muitos desses trabalhadores, por falta de qualificação profissional, foram dispensados pela empresa depois de um ou dois anos de serviços prestados e, aos poucos, retornam à atividade anterior de produção de farinha. Em 2010, ocorreu uma carência do produto e, assim, houve uma supervalorização em que um saco de farinha de 50 quilos chegou a custar $\mathrm{R} \$ 150,00$ ou R \$ 160,00 nas principais cidades do Amazonas e do Pará. Uma das causas da carência do produto foi a quantidade excessiva de chuva, que ocasionou o apodrecimento das raízes de algumas roças; outra causa foi o deslocamento de "pessoal que se dedicou ao trabalho das empresas contratadas e subcontratadas pela Alcoa e não fizeram roças o suficiente para atender a demanda regional" (JSA, 22 anos, oitava série).

Para o preparo da farinha, principalmente, são utilizados vários instrumentos, que ficam disponíveis no barracão. São usados como recipientes: "garera", "gamela", "cuia", "sacos", "bacia", "panelas"; para secagem da massa: "tipiti", "prensa"; para mexer a farinha no forno: "remo", "rodo", "pá”, "cuiapéua; para evitar que a massa no tipiti caia no chão:" rolha", "pano”, "ouriço de castanha", "cuia"; para carregar a mandioca da roça para o barracão: "paneiro", "saco"; para descascar a mandioca:"terçado", "faca", "raspador"; para serrar a mandioca: "motor de serrar mandioca", "ralo"; para torrar a farinha: "forno de barro", "forno de camburão de diesel", "forno de aço"; para peneirar a massa serrada: "peneiras" para a massa da farinha e para a massa dos beijus; para esticar o tipiti: "pau-do-tipiti" ; para alimentar a fornalha ardente do forno: "lenhas do roçado". 


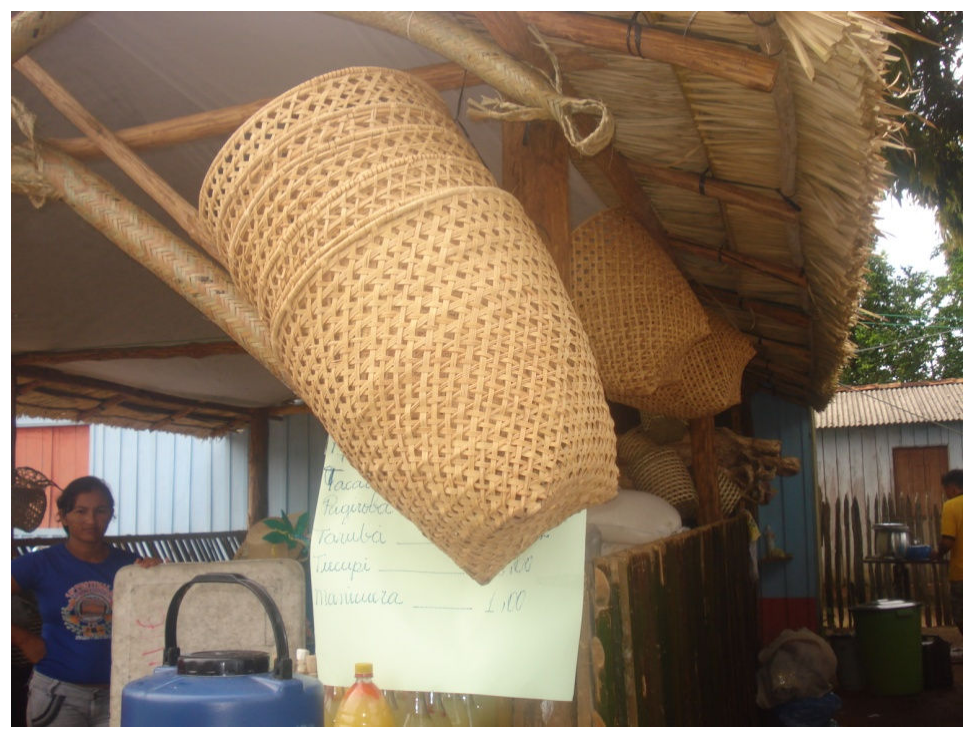

Fonte: Pesquisa de campo, 2010.

Figura 5 - Paneiros

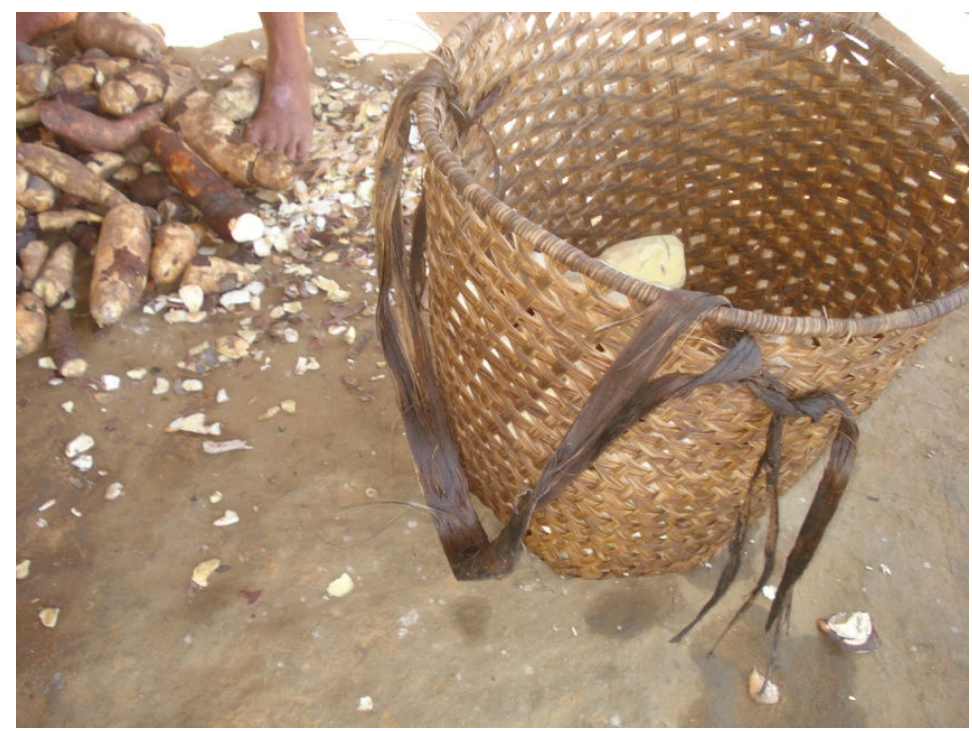

Fonte: Pesquisa de campo, 2010.

Figura 6 - Paneiro com envira (alça) 


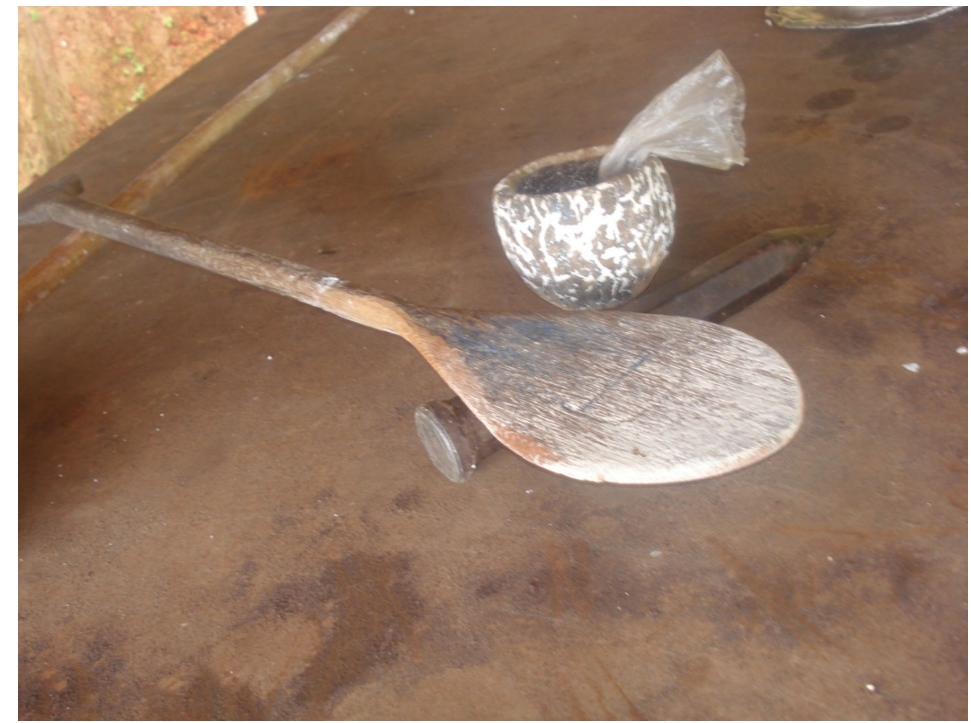

Fonte: Pesquisa de campo, 2010.

Figura 7 - O remo e a rolha

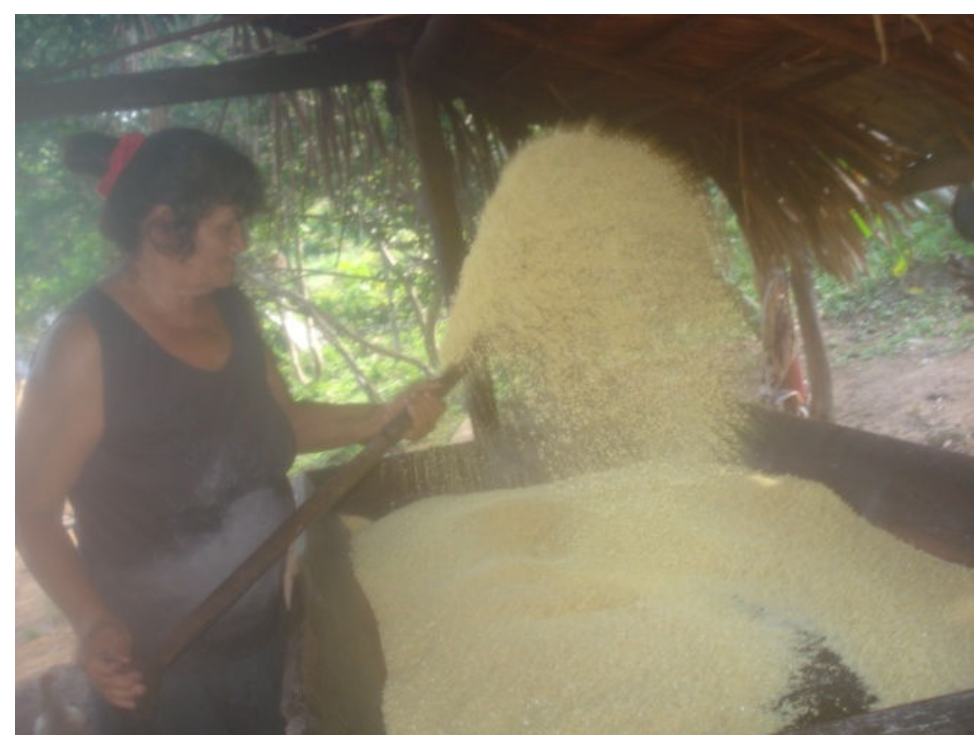

Fonte: Pesquisa de campo, 2010.

Figura 8 - Esfriando a farinha com o remo 


\subsection{Os subprodutos da mandioca}

A mandioca, que contém ácido cianídrico ( $\mathrm{HCN}$ ), não pode ser consumida in natura. Para torná-la consumível em diferentes subprodutos, é preciso obedecer às etapas de serragem, secagem e torragem, no caso da produção de qualquer tipo de farinha. A partir da massa podem-se obter os subprodutos que exigem diferentes maneiras de preparo. Assim, foi consenso na fala das pessoas os seguintes nomes:

- para beiju: "beiju cica", "beiju de moça", "beiju de pajiroba", "beiju de tarubá", "beiju d'água", "beiju de tapioca", "beiju peteca” ou "pé-de-moleque";

- para massas: "massa lavada", "carimã”, "crueira";

- para bebidas: "tarubá", "pajiroba”, "pajiroba picadinho”, "caissuma";

- para farinha: "farinha d'água", "farinha de toco mole", "farinha seca", "farinha de mistura", "farinha de tapioca";

- para frituras: "frito de farinha", "frito de tapioca", "croquete";

- para pratos: "panquecas","pato no tucupi”, "peixe no caldo do tucupi", "maniçoba".

Além desses derivados da mandioca também foram registrados outros, como: "mingau de farinha", "manicuera", "caribé”, "pirão", "chibé”, "tucupi”, "borra amarela”, "polvilho”, "tacacá", "bolo de macaxeira”, "bolo podre", "tapioquinha", "tapioca" e "biscoito".

Portanto, essas são as diferentes formas de se usar a massa da mandioca pelos moradores das comunidades do Igarapé do Juruti-Velho, e as mesmas denominações ou procedimentos de manuseio e preparo podem ser encontrados em outras comunidades tanto do Pará quanto do Amazonas. Muitos desses produtos são comercializados em pequena escala nas pequenas, médias e grandes cidades da Região Norte.

\section{Considerações Finais}

Com base nas entrevistas realizadas in loco com moradores do Baixo Amazonas, no Pará, foi possível fazer o levantamento lexical e a descrição etnográfica de aspectos relacionados à organização do trabalho do caboclo na roça, às variedades de mandioca, ao plantio da maniva, aos instrumentos usados para a produção da farinha e de seus derivados e em relação aos 
próprios subprodutos da massa da mandioca. Embora se tenha chegado a uma metalinguagem específica no que diz respeito à cultura da mandioca praticada nas comunidades do Igarapé do Juruti-Velho, mediante a realização de entrevistas com os moradores locais durante alguns dias da última semana do mês de agosto de 2010, a composição do léxico pode ser maior, de modo que, para descrevê-lo e observar o comportamento linguístico dos moradores, exigiria mais tempo de contato no barracão, nos "centros" e na roça. Apesar disso, a linguagem descrita na pesquisa caracteriza bem o roceiro e sua relação com a cultura da mandioca, servindo aos propósitos almejados e a natureza deste trabalho. Nesse sentido, os itens lexicais relacionados se bastam, uma vez que são os mais conhecidos da região. O homem roceiro é detentor de um conhecimento tradicional herdado dos índios sobre a cultura da mandioca, e se correlaciona com o mundo da roça ao usar um vocabulário típico, que foi parcialmente descrito no corpo do trabalho e acrescentado ao glossário de termos relacionados à cultura da mandioca no apêndice desta pesquisa.

\section{Apêndice}

Glossário de termos relacionados à cultura da mandioca usados no Igarapé do Juruti-Velho pelos moradores locais

\section{A}

1. Acabar - v.t.d. 1. Resultar. 2. Trazer como consequência.

2. Achadinha - s.f. 1 É uma variedade de mandioca cultivada na região amazônica e de casca na cor vermelho arroxeada.

3. Aguar - v.t.d. 1. Dissolver a tapioca na água para remover o ácido cianídrico (HCN).

4. Ajuda - s.f. 1. Variedade de mandioca.

5. Amadurecer - v.i. 1. Tornar-se maduro.

6. Âmago - s.m.1. O tubérculo. 2. A raiz. 3. A parte mais central da raiz da mandioca.

7. Amarelaça — adj. 1. Variação de amarela ou amarelada em referência a cor da mandioca.

8. Ambé - s.m.1. O mesmo que imbé. O cipó do qual se faz o paneiro para carregar mandioca. 
9. Ananás - s.m. 1. É o rolo com dentes usado para serrar mandioca. 2. A fruta.

10. Anuecê - s.f. 1. Espécie de mandioca não caracterizada pelos informantes.

11. Ajuri - s.m. 1. Puxirum. 2. Mutirão. 3. Reunião de pessoas para trabalhar no roçado de alguém sem remuneração.

12. Areia - s.f. 1. É uma espécie de solo arenoso.

13. Areião - s.m.1. É o mesmo que solo arenoso.

14. Armar o beiju - v.t.d. 1. É deixar o beiju no ponto para assar. 2. Preparar o beiju para ser assado.

15. Arpão - s.m.1. Espécie de mandioca cujo caule é grosso e comprido.

16. Aruanã - s.m. 1. Espécie de mandioca cuja cor da segunda casca é vermelha.

17. Atorar - v.t.d. 1. Cortar.

18. Avermelhar - - v.i. 1. Tornar-se vermelho.

B

19. Bago - s.m. 1. O grão da farinha. 2. O caroço.

20. Barracão - s.m. 1. O lugar onde produz a farinha no interior.

21. Batata - s.f. 1. A raiz da mandioca. 2. O tubérculo.

22. Batata doce - s.f. 1. É uma raiz tuberosa, que dá a coloração rosa ao pajiroba.

23. Beiju cica - s.m. 1. O subproduto da mandioca dura, que é colocado diretamente no forno.

24. Beiju d'água - s.m. 1. O subproduto da mandioca mole, ou seja, da mandioca que fica na água. O beiju é envolto em folhas de bananeira.

25. Beiju de crueira - s.m. 1. É o subproduto da mandioca feito com as sobras na peneira, que depois de colocadas ao sol para secarem são socadas em um pilão, de modo que se tornam um pó apropriado para fazer beiju no forno ou sobre outro recipiente levado ao fogo.

26. Beiju de tapioca - s.m. 1. O subproduto da mandioca feito geralmente em uma frigideira sobre o fogo 2. O mesmo que tapioquinha.

27. Beiju de tarubá - s.m. 1. É um beiju grande igual ao do pajiroba, mas com uma única diferença: é bem assado e é específico para a bebida chamada tarubá. 
28. Beiju grosseiro - s.m.1. É um beiju grande, que adquire a coloração vermelha no forno e é específico para fazer pajiroba.

29. Beiju pé-de-moleque - s.m. 1. O subproduto da mandioca cuja massa precisa ser escaldada para ligar e ir ao forno envolto em folha de bananeira 2. O mesmo que beiju peteca.

30. Beiju peteca - s.m. 1. O subproduto da mandioca cuja massa precisa ser escaldada para ligar e ir ao forno em folha de bananeira. 2. O mesmo que beiju pé-de-moleque.

31. Bera - s.f. 1. Variação de beira. 2. A margem do Igarapé do JurutiVelho.

32. Beradão - s.m. 1. Variação de beiradão. 2. A margem do Igarapé do Juruti-Velho.

33. Bodó - s.m. 1. Espécie de mandioca de massa amarela e caule alto.

34. Borra amarela — s.f. 1. A camada amarela e residual da mandioca que fica sobre a tapioca.

35. Braba - adj. 1. Variação de brava dada à mandioca com muito ácido cianídrico.

36. Braço da maniveira - s.m. 1. O pecíolo que liga a folha ao caule.

37. Branca - s.f. 1. Variedade de mandioca cuja cor é amarela e é indicada para fazer, além da farinha, os beijus.

38. Brebrei - $a d v$. 1. A maneira como são arrumadas as mandiocas no paneiro. 2. Só jogado.

39. Broa - s.f. 1. É o subproduto da mandioca feito da tapioca.

C

40. Caba - s.f. 1. O mesmo que vespa.

41. Cabeça do paneiro - s.f. 1. É a forma como são arrumadas as mandiocas maiores e compridas na parte de cima do paneiro.

42. Caibro - s.m.1. É o caule roliço de árvores, o qual é usado na cobertura do barracão.

43. Caissuma - s.m. 1. O mesmo que pajiroba, a bebida tomada no roçado durante o ajuri.

44. Caititu - s.m. 1. É o nome da roda grande, onde dois homens a giram para que ela serre as mandiocas 2 . É o nome de um dos porcosdo-mato da região.

45. Caixa - s.f. 1. O objeto posto sobre o rolo com dentes cuja função é evitar que a massa da mandioca se espalhe por todas as direções. 
46. Camarãozinho - s.m.1. Espécie de mandioca cujo arvoredo é baixo e a popa é amarela.

47. Capinar - v.t.d. 1. Cortar o mato, o capim com o terçado.

48. Capoeira - s.m.1. É a roça, que teve todas as suas mandiocas retiradas.

49. Capoeirão - s.m. 1. É a roça, que teve todas as suas mandiocas retiradas, mas desta vez o mato já cresceu muito.

50. Carga de burro - s.f. 1. Espécie de mandioca com casca marrom e massa amarela.

51. Caribé - s.m. 1. É uma espécie de mingau de farinha de mandioca.

52. Carimã - s.m. 1. É a massa da mandioca que, depois de lavada, se põe para secar no forno. Com ela se faz frito, mingau e beiju.

53. Cariúba - s.f. 1. Madeira usada para fazer os esteios do barracão.

54. Carlitozadas - s.m. plural.1. Relativo à família Carlitos, pessoas moram na comunidade Raifran no Igarapé do Juruti-Velho.

55. Cavalo - s.m.1 $\mathrm{O}$ instrumento onde está o conjunto de acessórios usados para serrar a mandioca 2 . O acessório de madeira sobre o qual fica o motor de serrar mandioca. 3. O animal quadrúpede.

56. Caxiri. - s.m. 1. O nome indígena para pajiroba, a bebida que os índios produziam, cuja fermentação era por eles creditada ao cuspe que adicionavam à seiva da mandioca.

57. Centro - s.m. 1 O lugar distante da casa do caboclo, onde ficam a roça, o barracão e o chavascal.

58. Chamuscar - v.t.d. 1. Assar levemente sobre a brasa.

59. Chavascal - s.m. 1. É o terreno alagado pelas águas do riacho, onde há muitas palmeiras como açaizeiros e buritizeiros.

60. Chibé - s.m. 1. É a farinha misturada com água natural.

61. Chumbo - s.m. 1. Nome dado à farinha de tapioca que senta no fundo do café por ser de má qualidade.

62. Coraci - s.f. 1. É uma espécie de mandioca de cor branca cultivada na região amazônica e é considerada muito brava para alguns informantes, enquanto outros consideram que não.

63. Coraci amarela - s.f. 1. Espécie de mandioca cuja massa é amarela.

64. Coraci branca - s.f. 1. Espécie de mandioca cuja massa é branca.

65. Coraci preta - s.f. 1. Espécie de mandioca que recebe esse nome devido ao caule e à casca serem da cor preta.

66. Cozinha de farinha - s.f.1. O mesmo que barracão, o lugar onde se produz farinha. 
67. Crueira - s.f. 1. É a sobra da massa da mandioca que não passa na peneira.

68. Cuí - s.m. 1. Os grãos mais finos da farinha.

69. Cumeeira - s.f. 1 . O vértice da cobertura do barracão ou a parte mais alta dele.

70. Cuiapéua - s.f.1.É um instrumento feito de cuia usado para remexer a farinha no forno.

71. Curumim - s.m.1. O nome da planta em cujas folhas são colocados os beijus do tarubá.

D

72. Dar - v.t.d. 1. Produzir. 2. Presentear, doar.

73. Decotar - v.t.d. 1. O mesmo que cortar as manivas. 2. Tirar as mandiocas do tronco com o terçado.

74. Demorar - vi. 1. Levar tempo para amadurecer.

75. Derribar - v.td.1. Cortar a arvore no tronco. 2. Variante de derrubar.

76. Descascar - v.t.d. 1. Remover as cascas da mandioca com a faca, raspador ou terçado.

E

77. Enfornar - v.t.d. 1. Levar a massa da mandioca para o forno quente, onde se transformará em farinha.

78. Envira - s.f. 1. A fibra de origem vegetal usada no paneiro como alça que é posta na testa da pessoa. 2. A árvore envira. Variante de embira.

79. Empachada - adj. 1. Com a barriga empanturrada de comida ou de bebida. 2. Com a barriga dura ou cheia de vento.

80. Empoar o peixe para fritar - v.t.d. 1. O mesmo que empanar o peixe com a massa da crueira ou da farinha, para fritar.

81. Enxada - s.f. 1. Utensílio usado para cavar o buraco onde serão enterradas as manivas.

82. Escaldar - v.t.d1. Jogar a água quente sobre a massa, a farinha ou qualquer outro objeto.

83. Espalhadera - s.f. 1. Variação de espalhadeira. 2. É a pessoa que joga os pedaços de maniva no buraco para serem plantados.

84. Espanta-molhe - s.m. 1. O nome de um dos centros do Igarapé do Juruti-Velho. 
85. Estaca - s.f. 1. O caule da maniveira.

86. Estaca grande - s.f. 1. Espécie de mandioca com caule longo e com massa branca.

87. Estaquinha - s.f. 1. Espécie de mandioca com caule amarelo e com massa amarela.

88. Esteio - s.m. 1. O caule roliço e grosso, que sustenta a cobertura do barracão.

F

89. Farinha d'água - s.f. 1. A farinha feita com a massa da mandioca que ficou na água durante alguns dias para amolecer.

90. Farinha da mandioca seca - s.f. 1. É a farinha feita unicamente da mandioca dura.

91. Farinha de mistura - s.f. 1. É o produto principal da mandioca, que serve como completo alimentar.

92. Farinha de tapioca. - s.f. 1. É a farinha feita com a massa da tapioca.

93. Filhas de mandioca - s.f. plural. 1. As mandiocas pequenas.

94. Fofa - s.f. 1. O mesmo que farinha.

95. Fora - $a d v$. 1. O Igarapé do Juruti-Velho em relação aos centros.

96. Fornada - s.f. 1. É o processo de torragem de farinha ligado ao tempo. Por exemplo, "esta é a minha primeira fornada".

97. Fornalha - s.f. 1. É a fogueira alimentada com lenha dos roçados e fica embaixo do forno.

98. Forno - s.m. 1. É uma chapa de aço em formato circular, onde se torram a farinha e outros derivados da mandioca.

99. Frito de crueira - s.m. 1. É o subproduto da mandioca feito com as sobras na peneira, que, depois de colocadas ao sol para secarem, são socadas em um pilão, de modo que viram pó que pode ser frito no óleo de cozinha.

G

100. Gamela - s.f. 1. O recipiente de madeira usada para se lavar as mandiocas.

101. Garera - s.f. 1. O recipiente feito do tronco oco de árvore destinado a receber a mandioca lavada ou a mandioca serrada. 
102. Goma - s.f. $1 \mathrm{O}$ amido da mandioca. 2. O mesmo que tapioca. 3. A água com tapioca levada ao fogo adquire uma consistência pastosa e clara.

103. Gravatar - v.t.d. 1. Retirar cuidadosamente o toco da mandioca para evitar o desperdício de massa.

104. Graúda - adj. 1. É o nome dado à mandioca grossa e comprida.

105. Gruta - s.f. 1. O local onde a água brota da terra. 2. O local onde passa o riacho nos centros do Juruti-Velho.

H (Sem dados)

I

106. Iá - s.f. 1. Espécie de mandioca de massa e casca brancas.

107. Igarapé - s.m. 1. Braço de rio. 2. Rio pequeno.

108. Inajá - s.m. 1. Espécie de mandioca cuja maniveira não cresce alta e possui massa amarela.

109. Impurrar - v.t.d. 1. Variação de empurrar. 2. Impelir com violência.

110. Incardida - adj. 1. Manchada. Variante de encardida.

111. Ingrossar - v.i. 1. Variante de engrossar. 2. Tornar mais grosso.

112. Interrar - v.t.d. 1. Variação de enterrar. 2. Pôr embaixo da terra.

113. Iscaldar - v.td. 1. Variação de escaldar. 2. Jogar água quente na massa. 3. Colocar a massa da mandioca no forno quente para que torre.

114. Ispocar - v.i. 1. Variante de espocar. 2. Estourar.

115. Ispremer - v.t.d. 1. Variante de espremer. 2. Comprimir para extrair o suco.

$\mathrm{J}$

116. Jacaré - s.f. 1. A cobertura feita de palha rocha, que fica no vértice para evitar que chova no barracão. 2. O mesmo que capote. 3. O animal réptil de sangue frio.

117. Jacitara - s.f. 1. A planta que cresce sobre as árvores, da qual se retira a tala para fazer o tipiti.

118. Jacuba - s.f. 1. É a mistura de leite líquido com açúcar e com farinha.

119. Jambu - s.m. 1. Planta rasteira cujas folhas e caule são fervidos para serem adicionados ao tacacá.

120. Jerimum - s.m. 1. Espécie de mandioca com guia alta, que possui a massa amarela e a casca marrom. 3. Abóbora. 
121. Jurutizinho - s.m. 1. Espécie de mandioca com caule amarelo e pecíolo vermelho.

122. Judiar - v.t.i. 1. Maltratar.

L

123. Lacrau - s.m. 1. Escorpião.

124. Lanternazadas - s.f. plural. 1. Relativo à família dos Lanternas, que moram na comunidade Raifran, no Igarapé do Juruti-Velho.

125. Largata — s.f. 1. Variação de lagarta.

126. Leandra - s.f. 1. Espécie de mandioca de vários ramos, que possui a casca e a maniva vermelhas.

127. Leite de mandioca - s.m. 1. É o líquido branco que sai da mandioca quando cortada.

128. Levar - v.i. e v.t.d. 1. Demorar. 2. Carregar.

129. Liguenta - adj. 1. Mais pegajosa ou grudenta.

M

130. Macaxeira - s.f. 1. É uma espécie de mandioca, que pode ser consumida in natura 2. Mandioca mansa. Em outras regiões do Brasil, é o mesmo que aipim.

131. Macaxeira amarela - s.f. 1. Espécie de macaxeira com popa e folha amarela.

132. Macaxeira manteiga - s.f. 1. Espécie de macaxeira com popa branca e com casca fina.

133. Macaxeira jabuti - s.f. 1. Espécie de macaxeira com casca vermelha e popa branca.

134. Macaxeira vermelha - s.f. 1. Espécie de macaxeira com popa vermelha e com casca vermelha.

135. Machado - s.f. 1. É o instrumento que tem o cabo de madeira e a lâmina de ferro presa em uma das extremidades, usado para partir madeiras para lenhas e para derrubar árvores no roçado.

136. Mãe da mandioca - s.f. 1. É o nome dado às mandiocas grandes.

137. Mancha de mandioca - s.f. 1. É o nome dado à nódoa provocada pelo leite pegajoso da mandioca, na roupa.

138. Mandiocona - s.m. 1. Expressão usada para se referir à mandioca grande. 
139. Manicujá - s.m. 1. O buraco onde são colocados os dois pedaços de maniva.

140. Manicuera - s.f. 1. Espécie de mandioca apropriada unicamente para fazer tucupi. 2. O subproduto dessa mandioca parecido com uma bebida ou mingau.

141. Maniva - s.f. 1. O caule da planta. 2. A árvore da mandioca.

142. Maniveira - s.f. 1. A árvore da mandioca

143. Marrequinha - s.f. 1. Variedade de mandioca cujo amadurecimento no solo é rápido e é excelente para produção de tapioca.

144. Massa - s.f. 1. É a mandioca depois de serrada.

145. Massapé - s.m. 1. É uma espécie de solo argiloso. 2. O mesmo que barro.

146. Menina - s.f. 1. Espécie de mandioca com caule grosso e com raízes grandes.

147. Mingau de crueira - s.m. 1. O subproduto da mandioca feito com as sobras deixadas na peneira, que depois de colocadas ao sol para secarem, são socadas em um pilão, de modo que pode ser aproveitado em forma de mingau.

148. Mingau de farinha $-s . m$. 1 . O subproduto da mandioca em que se pode acrescentar leite, castanha etc.

149. Miriti - s.f. 1. Variedade de mandioca cuja cor é amarela.

150. Misgalha - v.t.d. 1. Variante de misgalhar. 2. Reduzir em pedaços menores.

151. Moitá - s.m. 1. O lugar na mata onde se espera a caça passar.

152. Moorta - s.f. 1. Um das madeiras usadas para fazer os caibros do barracão.

153. Motor-serra - s.m. 1. A máquina usada para serrar mandioca.

154. Muralha - s.f. 1. As paredes feitas de barro que sustentam o forno em cima.

$\mathbf{N}$ (Sem dados)

O

155. Olho - s.m. 1. É o nome dado no Igarapé do Juruti-Velho para as gemas florais. 2. O mesmo que broto 3. O órgão da visão.

156. Olímpia - s.f. 1. Espécie de mandioca da cor amarela cujo arvoredo é alto. 
157. Pá - s.f. 1. Utensílio feito de madeira para mexer a farinha no forno.

158. Pagoa - s.f. 1. Espécie de mandioca da popa branca, própria para fazer beiju.

159. Paixão - s.f. 1. Variedade de mandioca da cor amarela.

160. Pajiroba. s.m.1. É uma espécie de bebida feita a partir de beijus grandes da massa da mandioca com a coloração rosa devido à presença da batata doce. 2. É a cachaça de origem indígena. 3. Caissuma. 4. Caxiri.

161. Paneirada - s.f. 1. É o paneiro cheio de mandioca que se descarrega no barracão ou na água. 2. É o carregamento de mandioca no paneiro.

162. Paneiro - s.m. 1. O utensílio de origem indígena usado para carregar mandioca.

163. Parte - v.t.d. 1. Variante de partir. 2. Quebrar-se.

164. Pau caboclo - s.m. 1. Madeira usada para fazer os caibros do barracão.

165. Pau do tipiti - s.m. 1. É uma vara resistente ao peso das pessoas ou de toras de madeira cuja função é esticar o tipiti para secar a massa da mandioca em seu interior.

166. Peneira - s.f. 1.Utensílio de origem indígena feito de tala de ambé (o mesmo que imbé) ou de chapa de aço com furos, por onde passa a massa da mandioca antes de ir ao forno para torrar.

167. Perereca - s.f. 1. Espécie de mandioca cuja maniveira é baixa e possui a casca marrom e a massa branca.

168. Pirão - s.m. 1. É a farinha escaldada com água quente.

169. Plantar em pé - Expressão usada para o plantio inclinado dos dois pedaços de maniva na cova.

170. Plantar deitada - Expressão usada para o plantio de forma horizontal dos dois pedaços de maniva na cova.

171. Polvilho - s.m. 1. É a tapioca seca, da qual se pode fazer biscoito torrado, pão-de-ló etc.

172. Popa - s.f. 1. O mesmo que raiz. 2. A massa da mandioca in natura.

173. Pororoca - s.f. 1. É uma variedade de mandioca cultivada na região que possui raízes grandes.

174. Pororoquinha - s.f. 1. É uma espécie de mandioca pequena.

175. Prensa - s.f. 1. É o instrumento de secagem da massa da mandioca mais eficiente devido a maior capacidade de armazenamento.

176. Presta - vi. 1. Variante de prestar. 2. O mesmo que ser útil.

177. Puçanga - s.f. 1. É o ato de mastigar o beiju do pajiroba para que a bebida fermente ou para que fique mais doce. 
178. Purridão - s.f. 1. Variante de porridão. 2. O mesmo que bêbado, derivado de porre.

179. Puxirum - s.m. 1. É a reunião de trabalhadores na roça para ajudar alguém a plantar a maniva, a capinar ou mesmo para fazer o roçado. 2. O mesmo que ajuri ou mutirão.

Q

180. Queroizadas - s.m. plural. 1. Relativo à família dos Queiróz, que moram na comunidade Raifran, no Igarapé do Juruti-Velho.

$\mathbf{R}$

181. Raiz - s.f. 1. A mandioca. 2. O tubérculo da planta maniveira.

182. Ralo - s.m. 1. Objeto com dentes e forma retangular feito de lata de querosene ou de lata de óleo de cozinha cuja função é ralar a mandioca.

183. Ramalhuda - adj. 1. Mandioca com vários ramos ou galhos.

184. Raspar - v.t.d. 1. Umas das formas de descascar a mandioca.

185. Raspador — s.m.1. Objeto em forma de "U" com uma lâmina presa às extremidades cuja função é descascar a mandioca.

186. Rastejar - v.t.d. 1. O mesmo que esfregar com o toco da mandioca o resto da outra no ralo.

187. Remo - s.m.1. Objeto feito de madeira usado no casco pelo ribeirinho para se locomover pelos igarapés e lagos, além de ser usado também para remexer a farinha no forno.

188. Rodo - s.m. 1. O instrumento de madeira com cabo longo inserido em uma peça retangular, cuja função é remexer a farinha no forno.

189. Roça - s.f. 1. O terreno onde se planta a mandioca ou outras culturas.

190. Roçado - s.m. 1. O terreno destinado a fazer a roça de mandioca ou outras culturas.

191. Roceiro - s.m. 1. A pessoa que cultiva culturas em um terreno chamado roça.

192. Rolha - s.f. 1. O ouriço de castanha colocado na cabeça do tipiti, cuja função é impedir que a massa derrame.

193. Rosarinho - s.m. 1. Espécie de mandioca com casca vermelha, com guia roxa e com massa amarela.

S

194. Santospé - s.m. 1. O mesmo que centopeia.

195. Sociedade - s.f. 1. Sistema de partilha de produção de farinha entre o dono da plantação da mandioca e o interessado. 
196. Sevada - adj. 1. Mandioca depois de serrada, ou ralada.

197. Socó - s.m. 1. Espécie de mandioca com massa amarela e caule comprido. 2. Espécie de ave aquática, que se alimenta de peixes.

T

198. Tacacá - s.m. 1. É a tapioca adicionada à água que, com a fervura, adquire uma consistência pastosa e clara, na qual são acrescentados camarão, jambu, tucupi e, eventualmente, pimenta.

199. Tambaqui - s.m. 1. Espécie de mandioca com caule roxo e com pecíolo vermelho. Espécie de peixe amazônico.

200. Tapaiúana - s.f.1. Espécie de mandioca com vários ramos que possui a casca marrom e a massa branca.

201. Tapioca - s.f. 1. O subproduto da mandioca de cor branca. 2. O amido da mandioca.

202. Tapioquinha - s.f. 1. É o beiju feito da massa da tapioca.

203. Tapiriti - s.f. 1. O mesmo que massa seca dentro do tipiti.

204. Tapurati - s.f. 1. Variação de tapiriti. O mesmo que massa seca.

205. Tarisca - s.f. 1. O rolo com dentes 2. Os dentes que serram (ralam) a mandioca.

206. Tarubá - s.m.1. É uma bebida pastosa feita na folha da planta chamada curumim.

207. Ter - v.t.d ou modal 1. Possuir. 2. Dever.

208. Terçado - s.m. 1. Utensílio usado na capinação da roça.

209. Terra de várzea - s.f. 1 É uma espécie de solo, que surge nas vazantes das águas e é muito rico em húmus.

210. Terra rocha - s.f. 1. É uma espécie de solo, rico em húmus.

211. Tipiti - s.m. 1. Utensílio de origem indígena usado para secar a massa da mandioca.

212. Toco - s.m. 1. A parte da mandioca que a liga ao tronco da maniveira.

213. Toco molhe - s.m. 1. É a mandioca que ficou na água. 2. A farinha d'água.

214. Traíra - s.f. 1. É uma espécie de mandioca cultivada na região cujas folhas são meio arroxeadas. 2. Uma espécie de peixe.

215. Tronco - s.m. 1. A parte grossa da maniveira junto às raízes da mandioca.

216. Tucumã - s.m. 1. Variedade de mandioca cuja cor é amarela. 2. A fruta do tucumanzeiro. 
217. Tucupi - s.m.1. O líquido extraído da massa da mandioca adicionado à água.

218. Tucupi puro - s.m. 1. O líquido extraído diretamente da massa da mandioca sem adicionar água.

$\mathbf{U}$ (Sem dados)

V

219. Vai-quem-quer - s.m. 1. O nome do centro da família Carlitos, no Igarapé do Juruti-Velho.

220. Vala - s.f. 1. O buraco cavado com a enxada, onde são enterradas as manivas.

221. Veneno - s.m. 1. O ácido cianídrico $(\mathrm{HCN})$.

$\mathbf{X}($ Sem dados)

Z

222. Zolhuda - s.f. 1. Espécie de mandioca com caule roxo e a raiz meio amarela.

\section{Referências}

ALTENHOFEN, Cléo Vílson; KLASSMANN, Mário S. (Orgs.) et al. Atlas Linguístico Etnográfico da Região Sul do Brasil (ALERS). Cartas semântico-lexicais. Porto Alegre: Editora da UFRGS; Florianópolis: Editora da UFSC, 2011.

CHISTÉ, Renan Campos et al. Quantificação de cianeto total nas etapas de processamento das farinhas de mandioca dos grupos seca e d'água. Acta Amaz., v. 40, n.1, p. 221-226, mar. 2010.

CORREA, Hydelvidia Cavalcante de Oliveira. O falar do caboco amazonense: aspectos fonético-fonológicos e léxico-semânticos de Itacoatiara e Silves. Rio de Janeiro: PUC, 1980.

CRUZ, Maria Luíza de Carvalho. Atlas Lingüistico do Amazonas (ALAM). 2004. Tese (Doutorado em Letras Vernáculas) - Universidade Federal do Rio de Janeiro, Rio de Janeiro. 2004. 
EMBRAPA. Mandioca e fruticultura. [s.d.]. Disponível em: < http:// www.cnpmf.embrapa.br/index.php?p=pesquisa-culturas_pesquisadasmandioca.php>. Acessado em: 15 ago. 2010.

FAUSTO, Carlos. Uma plantinha venenosa. Ciência hoje, Rio de Janeiro, v. 39, p. 37-39, 2006.

FERREIRA, Aurélio Buarque de Holanda. Novo dicionário de língua portuguesa. 2. ed. Rio de Janeiro: Nova Fronteira, 1986.

GONZAGA, Adriana Dantas et al. Toxicidade de manipueira de mandioca (Manihot esculenta Crantz) e erva-de-rato (Palicourea marcgravii St. Hill) a adultos de Toxoptera citricida Kirkaldy (Homoptera: Aphididae). Acta Amaz., v. 38, n. 1, p. 101-106, dez. 2008.

HOUAISS, Antonio et AL. Dicionário Houaiss da lingua portuguesa. Rio de Janeiro: Objetiva, 2009.

MENDES, Rui Américo et al. Mapeamento da distribuição geográfica das espécies silvestres brasileiras de Manihot, com vistas à conservação dos parentes silvestres e das variedades crioulas da Mandioca (Manihot esculenta Crant:) In: CORADIN, Lidio. (Coord.). Parentes silvestres das espécies de plantas cultivadas. Brasília, DF: Ministério do Meio Ambiente, 2006. p. 29-32.

PEZZUTI, Juarez; CHAVES, Rodrigo Pádua. Etnografia e manejo de recursos naturais pelos índios Deni, Amazonas, Brasil. Acta Amaz, v. 39, n. 1, p. 121-138, mar 2009.

RODRIGUES JÚNIOR, Adail Sebastião. Etnografia e ensino de línguas estrangeiras: uma análise exploratória de seu estado-da-arte no Brasil. Linguagem \& Ensino, v. 10, n. 2, p. 527-552, jul. 8 dez. 2007.

SOUZA, Joana Maria Leite de et al. Caracterização físico-química de farinhas oriundas de variedades de mandioca utilizadas no vale do Juruá, Acre. Acta Amaz, v. 38, n. 4, p. 761-766, dez. 2008. 